\title{
Healthcare Building Sustainability Assessment tool - Sustainable Effective Design criteria in the Portuguese context
}

\author{
Maria de Fátima Castro*, Ricardo Mateus, Luís Bragança \\ University of Minho, Territory, Environment and Construction Research Centre, Campus de Azurém, 4800-048 Guimarães, Portugal
}

\begin{abstract}
A B S T R A C T
Tools and methods to improve current practices and quality in the healthcare building sector are necessary to support decision-making at different building life cycle phases. Furthermore, Healthcare Building Sustainability Assessment (HBSA) Methods are based on criteria organised into different levels, such as categories and indicators. These criteria highlight aspects of significant importance when designing and operating a sustainable healthcare building. To bring more objectivity to the sustainability assessments, the standardisation bodies (CEN and ISO) proposed core indicators that should be used in the evaluation of the environmental, societal and economic performances of buildings. Nevertheless, relying on state of the art analysis, it is possible to conclude that there are aspects of major importance for the operation of healthcare buildings that are not considered in the HBSA methods.

Thus, the aim of this paper is to discuss the context of sustainability assessment methods in the field of healthcare buildings and to present a proposal for the incorporation of Sustainable-Effective Design (SED) criteria in a new HBSA method. The used research method is innovative since in the development of the list of sustainability criteria it considers the opinion of main healthcare buildings' stakeholders, the existing healthcare assessment methods and the ISO and CEN standardisation works in the field of the methods to assess the sustainability of construction works. As a result, the proposed method is composed of fifty-two sustainability indicators that cover the different dimensions of the sustainability concept to support decision making during the design of a new or retrofitted healthcare building in urban areas.
\end{abstract}

\section{Introduction}

Green and sustainable buildings have become popular research areas over the past two decades. The concept of Sustainability maybe is a near-impossible term to clearly define, but healthcare and climate change are important enough to draw the attention of all stakeholders. Healthcare industry is just beginning to articulate the impact of climate change on healthcare services delivery.

The launch of Healthcare Building Sustainability Assessment (HBSA) methods is accelerating the implementation of a range of global market-competitive sustainable healthcare building strategies in worldwide projects. A healthcare building is a complex, contradictory building type, and is a system of systems. It is a condensed aggregation of people, equipment and supplies (Verderber, 2010). For these reasons space planning should be a collaborative effort between architects and all other stakeholders. All the environmental, social and economic thinking in architecture continue to develop the different dimensions and integrative approaches to understand and address, and in some ways, also to go beyond, sustainability issues in the built environment. So it is important to answer the question: "How to generate sustainability concepts from architectural perspectives?" (Allacker and Khan, 2015).

The HBSA methods can certainly help to answer this question, integrating into its list of evaluation more and more criteria that correlate directly with the spatial architectural design. If it is not worth having sustainable spaces if they are not one hundred per cent used (otherwise the whole concept of sustainability would become irrelevant), then it is important to increasingly involve designers in the utilization of these kinds of tools.

In healthcare buildings, if the space planning is well executed it is easier to answer positively many of the criteria covered by existing HBSA methods, make all users feel comfortable and introduce sustainable technical improvements. Healthcare buildings are one of the best examples for all of these issues because its providers are not attending patients but helping people (Clark and Malone, 2006). This is a project where all basic design healthcare principles must be measured with increased care since both the well-being demands and users'

\footnotetext{
* Corresponding author.

E-mail addresses: info@mfcastro.com (M.d.F. Castro), ricardomateus@civil.uminho.pt (R. Mateus), braganca@civil.uminho.pt (L. Bragança).
} 
satisfaction are more sensitive (Castro et al., 2013).

According to Baum et al. (2009a), it is important to consider the dialogue that has been created around the synergies and potential conflicts between the two most significant trends currently shaping healthcare architecture and construction: Evidence-Based Design (EBD) and Eco-Effective Design (EED). EED support the improvement of indoor environmental quality and ecological health in the design and operation phases of healthcare buildings, which means that it takes into account the indoor comfort (e.g. visual, acoustic and thermal) and also the ecological issues related with the flows (e.g. water; energy and waste) necessary to maintain it. EBD focuses on the support of positive health outcomes through a growing number of solutions informed by practical knowledge and research in the design and operation of healthcare buildings. In this concept the well-being of the patients and staff is the main concern, and all the design decisions are focused on it. These two trends are having an impact on the design of healthcare architecture, but they are generally applied separately. However, more than $50 \%$ of the experts in these two trends enclosed concepts to consider that EBD and EED should work together in promoting benefits for each other (Baum and Shepley, 2009).

As an example, when designing patient rooms, there is a conflict between the interest of the users and the environment. Designing larger patient room provides more space, comfort and better conditions for the patient and medical staff. On the other hand, this will result in higher potential environmental impacts, due to the construction and operation of larger building spaces (Baum et al., 2009b).

Baum et al. (2009a) also consider that each intersection between these two concepts can lead to a new body of research and potentially new design directions. Based on the table presented by Baum et al. (2009b), called "Strategy Matrix", where authors described the relationship between EBD and EED criteria, Table 1 presents the conflicts and synergies between the EBD strategies (described in (Baum et al., 2009b)) and core categories of recognised HBSA methods, which reflect concerns clearly presented in EED. This table takes into account the core categories of the four most recognised HBSA methods existing in the market: LEED BD + C (Building Design and Construction); BREEAM UK New Construction; Green Star - Design \& As Built; and CASBEE - NC (New Construction) - already studied and compared elsewhere (Castro et al., 2015a).

Table 1 presents four levels of synergy potential: two extremes that symbolise the entire existence, or not, of synergy between two criteria; and two intermediate levels covering the possibility of conflicts or synergies between two categories. Analysing Table 1, there are rare exceptions like in the case of "Water" and "Transport" core sustainability categories, all categories are related to EBD strategies and are not in conflict with sustainability criteria.

Possible or clear synergies are the major results across all categories.

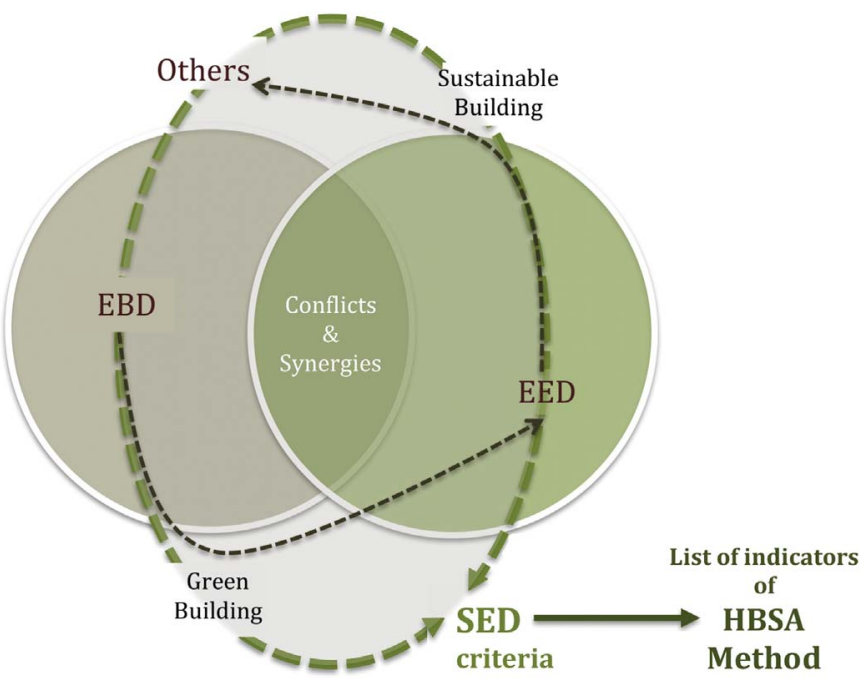

Fig. 1. Concept of Sustainable-Efficiency Design (SED)

On the other hand, the category "Service quality" is the one that has a "clear synergy" with all the main issues of the EBD concept. To better analyse and understand this relationship, all the criteria of each category and all the best practices of EBD must be considered. Therefore, it is important to analyse these conflicts and synergies to improve dialogue between these two realities and supply the common objective that is to support teams in the design and construction phases. So, it is essential to associate the EED with the EBD strategies and also with other concerns related to environmental, economic and societal issues to achieve a comprehensive list of sustainability criteria to consider in HBSA methods.

It is proposed the creation of a new concept, resulting from the sum of the concepts EED and EBB with other sustainability criteria: Sustainable-Effective Design (SED). As presented in Fig. 1, this newly proposed concept is a process of design that is based simultaneously on the traditional medical functionality principles and the best trade-off between the environmental, economic and societal concerns of the Sustainable Development.

\subsection{Aims and objectives}

After studying the state of the art, it is possible to identify some studies in the context of the HBSA methods, which examine and present solutions for: i) the development of new methods to assess and rate the sustainability of healthcare buildings, as in (Mateus and Bragança, 2011; Ali and Al Nsairat, 2009); ii) the environmental criteria used in

Table 1

Relationship between the core categories of HBSA methods and EBD strategies (based on (Castro et al., 2014; Baum et al., 2009b)).

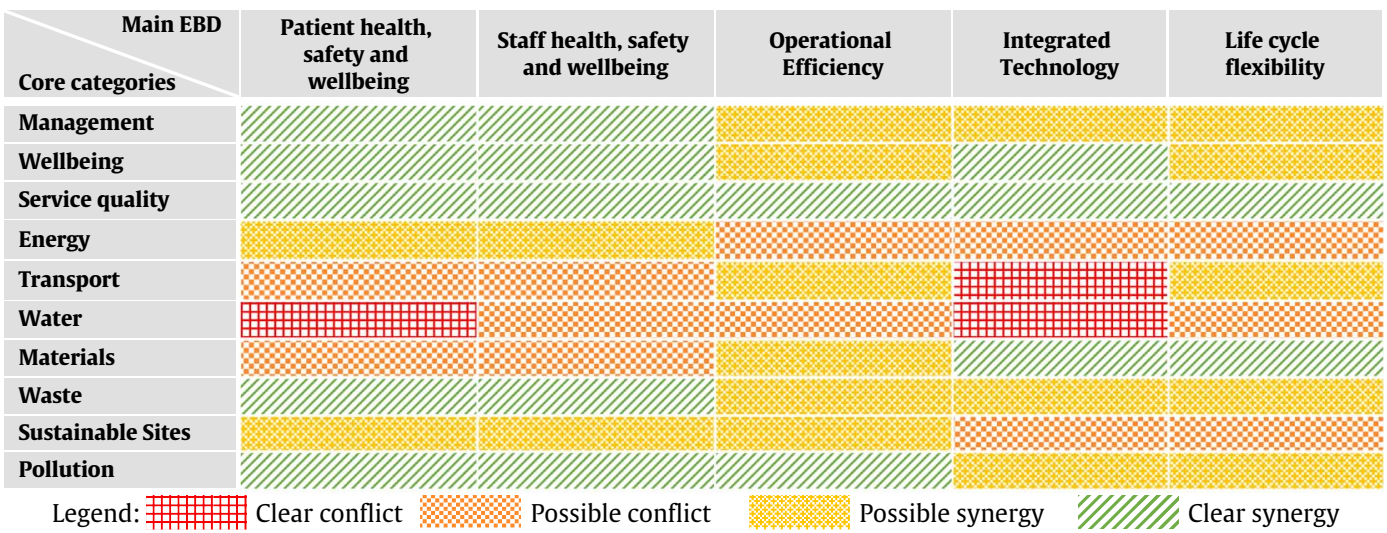


Environmental Assessment tools, as in (Haapio and Viitaniemi, 2007; Cotter et al., 2014); iii) the critical issues related to the assessment of the sustainability of healthcare facilities, as in (Stevanovic, 2015); iv) the specific space design concerns and special requirements of healthcare buildings, as in (Heynen, 2013); and the paradigm of designing healthcare buildings, bearing in mind the EED and EBD concepts, as in (Guenther, 2009). As a contribution to the development of state of the art studies, this paper aims at discussing and presenting a list of Sustainable-Effective Design (SED) indicators to be used in the development of a new HBSA method in the Portuguese context. The importance of each new proposed indicator was validated by a group of stakeholders using a questionnaire. Finally, the results are critically analysed.

Thus, the objectives are:

- Recommend specific SED indicators to be integrated into the structure of a new HBSA method, considering the efforts developed so far in the standardisation bodies (ISO and CEN), the most relevant HBSA methods and the recognised case studies;

- Adapt the proposed list of indicators to the Portuguese environmental, sociocultural and economic contexts;

- Validate the importance of considering the new proposed indicators;

- Present, as an example, the assessment method of one qualitative and one quantitative indicator;

- Demonstrate how it is possible to calculate the overall sustainability score;

- Discuss how the outcomes of this research can be used by managers, promoters, and designers to achieve more sustainable healthcare buildings.

\section{Methodology}

The first step of the implemented methodology is the definition of the list of the preliminary sustainability indicators to be integrated with the new HBSA method. This step is based on the analysis of the potential impacts and core sustainability criteria proposed by:

a) ISO 21929-1:2011 (ISO, 2011), CEN EN 15643-2:2011 (CEN TC 350, 2011), EN 15643-3:2012 (CEN TC 350, 2012a) and EN 156434:2012 (CEN TC 350, 2012b);

b) The existing HBSA methods. They were compared with each other at the level of the list of indicators, and with existing methods for other types of buildings;

c) The recognised sustainable case studies. To identify common sustainable principles considered in the design and operation of healthcare buildings.

Next step is to propose a list of SED indicators to be integrated with the Portuguese HBSA method in development - HBSAtool-PT. The aim is to develop a list of indicators wide enough to incorporate the most important sustainability criteria and also for practical use. To achieve this purpose, it was necessary to validate the preliminary list of indicators, namely those indicators that are not commonly considered in existing HBSA methods. This kind of procedure is regularly used by different authors as Kurtz et al. (2001) and Barbosa \& Almeida (2017).

For that, a questionnaire oriented to the key stakeholders involved in the context of hospital buildings was developed and implemented in Portugal. At the end of this step, the Analytical Hierarchy process (AHP) was used in the interpretation of results obtained in the questionnaire (Saaty, 2008). This process also allowed the definition of weights to be assigned to each SED indicator.

As a final step, the way as the SED indicators can be assessed is discussed in to define principles for the quantification of quantitative and qualitative indicators. As an example, at the end, the assessment method of qualitative and quantitative indicator is presented. This step also includes the definition of the structure of the HBSA method under development.

\subsection{Research method and definition}

The objective of the definition of SED criteria is to create a list of indicators that are at the same time simple, measurable and easily associated with the goals of Sustainable Development. These indicators are grouped into categories that fall into five different areas of sustainability: Environmental; Sociocultural and Functional; Economy; Technical; and Site.

The list is based on the development needs to meet up-to-date sustainable development targets, standardisation works and the specific context where the method is going to be applied. The method presented is focused on the Portuguese context, and consequently, it considers specific Portuguese aspects and regulations. Each category embraces the indicators that influence the building sustainability at that level. After that, the categories were distributed among the different sustainability areas. At a first step, three areas were defined, to assess the building performance at the level of the three main sustainability dimensions: environment, society, and economy. Since there are categories that match more than one main dimension, to improve the interpretation of results, two additional areas were created: Site and Technical (Castro et al., 2017).

This list was also defined considering the conflicts and synergies between EBD and EED data collected and studied. After the definition of the SED concept, the next step is to develop a list of indicators and at the end a system of evaluation.

In the context of HBSA methods, the evaluation system is crucial since it allows for the aggregation of the performance obtained at the level of the different indicators and a comparison to be made among the various buildings.

As a result of the new proposal and the HBSA method based on a better integration of SED criteria is expected:

- A broader and comprehensive list of sustainability indicators to support building stakeholders in the creation of a more sustainable healthcare sector will be established;

- Detailed information on healthcare buildings will be collected and organised. This can be used by building constructors, managers, owners and users to increase their performance;

- Benchmarks for the Portuguese healthcare buildings will be established by identifying conventional and sustainable performance levels (Castro et al., 2015b);

- A complete assessment and sustainability rating framework for both new buildings design and major renovations will be offered;

- The assimilation of sustainable practices will be facilitated, and the number of stakeholders with know-how in the field will be increased.

\subsection{Data collection}

The collection of data was made by interviews, to validate the proposed list of indicators and the HBSA method structure. An online questionnaire was prepared and sent to the main Portuguese stakeholders in the context of Portuguese healthcare buildings. Among other things, the questionnaire allowed the collection of the opinion of each group of stakeholders at the level of each proposed sustainability indicator.

The structure of the questionnaire is built in three parts. The first part is aimed at gathering the personal data related to the respondents (which job they have; the area of the country where they develop their activities, etc.). The second part presents the proposed structure for the method and requests the respondent to rank the relative importance of each indicator, category, and area. The third part is to collect comments and recommendations to improve the structure proposed.

This approach allowed to collect the data needed to understand the 
Table 2

Example of a table of the questionnaire to assess the relative weight of the indicators of a Category (Category C11 - Space flexibility and adaptability).

C11 - Space flexibility and adaptability

\begin{tabular}{llllllll}
\hline Indicator & 1 & 2 & 3 & 4 & 5 \\
\hline
\end{tabular}

I29 - Availability and accessibility to social areas

I30 - Space optimisation

I31 - Space flexibility

I32 - Space adaptability

relative importance of each indicator and to develop the relative weighting system.

Each respondent was requested to consider all tables existing in the questionnaire, where the indicators of each category and the categories of each area were presented. Each table was assessed individually, taking into account the graded scale defined in the questionnaire, from 1 (not important) to 5 (very important). They could also assign equal ratings to two or more indicators or categories. Table 2 presents an example.

\subsection{Sampling procedure}

The goal is to collect the opinion of the main groups of stakeholders: i) design teams and constructors, including those with expertise in the design and construction of sustainable healthcare buildings; and ii) healthcare building managers. In future, after this step of developing a specific and validated list of sustainability criteria, this list will be used to collect also the opinion of healthcare building users, including patients, visitors, medical and logistic staff.

At this moment, a group of stakeholders from different areas around the life cycle of healthcare buildings was chosen. The sample included: project designers (architects and engineers); sustainable construction experts; healthcare buildings managers; and professionals of the Portuguese National Health Service. To achieve the best results, all the participants were grouped into three main clusters:

I. Sustainable construction and healthcare building experts (qualified evaluators in Building Sustainability Assessment (BSA) methods and researchers in this field), designers and building industry professionals with more than five years of experience in construction or designing in the healthcare sector;

II. Healthcare buildings managers (for example, the Local Manager of Energy and Carbon) and professionals of the Portuguese National Health Service involved in strategic plans such as those in the field of energy consumption reduction;

III. Designers and building industry professionals with less than five years' experience in the healthcare context or the design of ecoefficient or sustainable buildings.

The sampling frame of cluster I is a list of experts endorsed by the Portuguese chapter of the International Initiative for a Sustainable Built Environment (iiSBE Portugal), by the Portuguese Association of Architects (OA) and the Portuguese Institution of Engineers (OE). The Portuguese National Health Service (SNS) provided the sampling frame of cluster II and cluster III that also include associates of the listed organisations that have less than five years of work experience.

The number of potential respondents was one hundred, and the total number of answers was sixty. The representativeness of each cluster in the sample is presented in Fig. 2: $54 \%$ for cluster I, $18 \%$ for cluster II and $28 \%$ for cluster III.

According to Saaty (1988), when there are clusters of different levels of expertise in a sample, the way they must contribute to the final results should also be different. Based on the same study, the considered influence of each cluster in the final results was: $45 \%$ for the Cluster I;

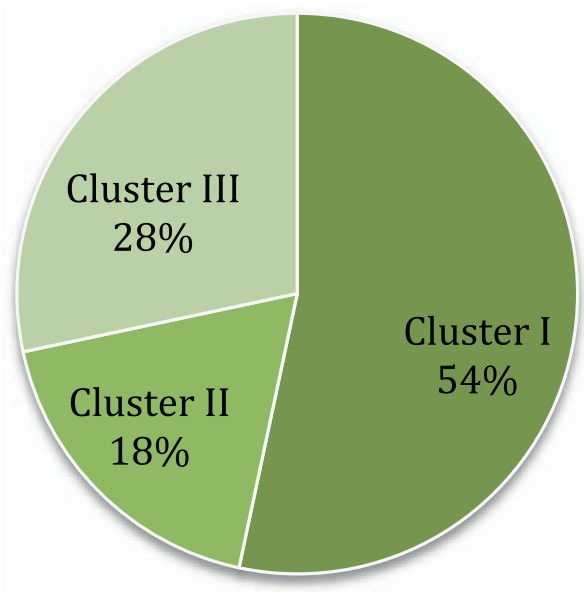

Fig. 2. Number of participants in each stakeholders' cluster.

$31 \%$ for the Cluster II; and 24\% for the Cluster III. Therefore, a higher weight was given to the judgment of those having higher proficiency in the field being analysed, independently of the number of respondents.

\subsection{Analytical Hierarchy Process (AHP)}

The Analytic Hierarchy Process (AHP) is a method of multi-criteria analysis, established in 1980 by Thomas L. Saaty. AHP is a mathematical technique to support decision-making procedure that provides efficient means multifaceted decision-making and that can help in complex and difficult decisions, taking into account a series of one-onone comparisons by supporting with recognised and weighting assortment criteria (Dweiri and Al-Oqla, 2006).

The following principles are the basis of AHP method (Saaty, 2008):

- Decomposition which structures the problem regarding its main components;

- Comparative judgments that are mandatory for paired comparison of criteria to establish criteria weights and investment alternatives;

- Synthesis of priorities, which dialogue the priorities of criteria and options for weights into a global rating, centred on which greatest option is decided upon.

2.4.1. Definition of the relative importance of each category and indicator For the definition of the average weights of each category or indicator, it is necessary to make paired comparisons, which are undertaken between categories and between indicators. For this purpose, and taking into account the scale of importance on the questionnaire - from 1 (the least) to 5 (the most important) - the respondents ranked the relative qualitative importance of each sustainability criterion.

Following the phases mentioned in Section 2.4, the stages of the AHP method used were (example of Environmental category) (Saaty, 1988):

1. To take into account the number of answers given (level 5) by each Cluster (I, II and III) for each category;

2. To do a paired comparison of selected categories, to set the relative importance between each two of them (C1 vs. C2, C1 vs. C3, C1 vs. $\mathrm{C} 4$, etc.). Then to make a judgment of the performance of the paired comparison of categories in achieving the goal.

3. To apply the AHP calculation process to synthesise paired comparisons. To weight the Eigenvector entries, hierarchical synthesis is used. By the sum of the weights of the criteria, it is taken as overall weighted eigenvector entries. The method chosen to calculate eigenvector was the ANC method (Hsiao, 2002). In this method, the figures of each column were divided by the sum of the columns. 
Table 3

Identification of new SED and EBD, EED in the structure of the HBSAtool-PT method.

\begin{tabular}{|c|c|c|}
\hline Area & Category & Indicator \\
\hline \multirow{16}{*}{$\begin{array}{c}\text { A1 } \\
\text { Environmental }\end{array}$} & $\begin{array}{l}\text { C1 - Environmental life cycle } \\
\text { impact assessment }\end{array}$ & I1 - Assessment of the building's life cycle impacts \\
\hline & \multirow{2}{*}{ C2 - Energy } & I2 - Primary energy consumption \\
\hline & & I3 - Local energy production \\
\hline & \multirow{7}{*}{ C3 - Soil use and biodiversity } & I4 - Layout optimisation \\
\hline & & I5 - Soil sealing \\
\hline & & I6 - Reuse of previously built or contaminated areas \\
\hline & & I7 - Ecological protection of the site \\
\hline & & I8 - Rehabilitation of the surrounding \\
\hline & & I9 - Use of native plants \\
\hline & & I10 - Heat island effect \\
\hline & \multirow{3}{*}{ C4 - Materials and Solid Waste } & I11 - Construction waste \\
\hline & & I12 - Reused products and recycled materials \\
\hline & & I13 - Waste separation and storage \\
\hline & \multirow{3}{*}{ C5 - Water } & I14 - Drinkable water consumption \\
\hline & & I15 - Recycling and recovery of effluents \\
\hline & & I16 - Treatment of contaminated effluents \\
\hline \multirow{16}{*}{$\begin{array}{l}\text { A2 } \\
\text { Sociocultural } \\
\text { and functional }\end{array}$} & \multirow{6}{*}{ C6 - User's health and comfort } & I17 - Natural ventilation \\
\hline & & I18 - Toxicity of finishing materials \\
\hline & & I19 - Thermal comfort \\
\hline & & I20 - Visual comfort \\
\hline & & I21 - Acoustic comfort \\
\hline & & I22 - Indoor air quality \\
\hline & \multirow{2}{*}{ C7 - Controllability by the user } & I23 - Ventilation and temperature \\
\hline & & I24 - Natural light \\
\hline & C8 - Landscaping & I25 - Visual link with the surrounding landscape \\
\hline & \multirow{2}{*}{ C9 - Passive design } & I26 - Layout and Orientation \\
\hline & & I27 - Passive Systems \\
\hline & C10 - Mobility plan & I28 - Accessibilities \\
\hline & \multirow{4}{*}{$\begin{array}{l}\text { C11 - Space flexibility and } \\
\text { adaptability }\end{array}$} & I29 - Availability and accessibility to social areas \\
\hline & & I30 - Space optimisation \\
\hline & & I31 - Space flexibility \\
\hline & & I32 - Space adaptability \\
\hline \multirow{3}{*}{$\begin{array}{c}\text { A3 } \\
\text { Economy }\end{array}$} & \multirow{2}{*}{ C12 - Life cycle costs } & I33 - Initial cost \\
\hline & & I34 - Operational costs \\
\hline & C13 - Local economy & I35 - Hiring local goods and services \\
\hline \multirow{12}{*}{$\begin{array}{c}\text { A4 } \\
\text { Technical }\end{array}$} & \multirow{4}{*}{$\begin{array}{l}\text { C14 - Environmental } \\
\text { management systems }\end{array}$} & I36 - Commissioning \\
\hline & & I37 - Environmental management plan \\
\hline & & I38 - Infection control \\
\hline & & I39 - Reducing noise pollution \\
\hline & C15 - Technical systems & I40 - Efficiency of mechanical systems \\
\hline & C16 - Security & I41 - Occupants safety \\
\hline & \multirow{2}{*}{ C17 - Durability } & I42 -Materials of high strength and durability \\
\hline & & I43 - Proper selection of furniture \\
\hline & \multirow{3}{*}{$\begin{array}{l}\text { C18 - Awareness and education } \\
\text { for sustainability }\end{array}$} & I44 - Education of occupants \\
\hline & & I45 - Education of service providers \\
\hline & & 146 - Satisfaction surveys \\
\hline & C19 - Skills in sustainability & I47 - Integration in the team of a qualified sustainability expert \\
\hline \multirow{5}{*}{$\begin{array}{l}\text { A5 } \\
\text { Site }\end{array}$} & C20 - Local community & I48 - Local community development \\
\hline & C21 - Cultural value & 149 - Heritage framework \\
\hline & \multirow{3}{*}{ C22 - Facilities } & I50 - Accessibility to public transport \\
\hline & & I51 - Low impact mobility \\
\hline & & I52 - Local amenities \\
\hline Legend: & SED criteria & EBD criteria \\
\hline
\end{tabular}


After, the element in each resulting row is added and divided by the number of parcels in the row ( $\mathrm{C} 1 \mathrm{vs}$. total sum of the ratios of column $\mathrm{C} 1$; $\mathrm{C} 2$ vs. total sum of the ratios of column $\mathrm{C} 1$; C3 vs. total sum of the ratios of column C1).

4. To incorporate consistency of results through the analysis of the degree of coherence among the paired comparisons. This is made, by calculating the following parameters: the Eigenvalue $\left(\lambda_{\max }\right)$; then the Consistency Index (CI) and Random Index (RI); and finally the Consistency Ratio (CR). If there is consistency in the analysis, it is possible to set the weights to be allocated to each of the categories under study.

Thus, to set the weight for each category and each indicator, a separate analysis was performed for each one of the five areas and each of the twenty-two categories respectively. The relative importance (relative weight) of each indicator and category was established using the square matrix structure (Hambali et al., 2010).

The numerical scores from the questionnaire revealed differences of opinion about the importance of each category and indicator. To study and analyse the data, a Relative Importance Index (RII) was used to calculate the final weight of the categories and the indicators (Othman et al., 2005; Fagbenle et al., 2011). The RII ranges from zero to one and is determined using Eq. (1), taking into consideration the opinion of the respondents and the weight assigned to each group of them (clusters).

$R I I_{c / i}=W I_{I}\left(\frac{\sum_{j=1}^{n_{I}} W_{j, I}}{A \times n_{I}}\right)+W I_{I I}\left(\frac{\sum_{j=1}^{n_{I I}} W_{j, I I}}{A \times n_{I I}}\right)+W I_{I I I}\left(\frac{\sum_{j=1}^{n_{I I I}} W_{j, I I I}}{A \times n_{I I I}}\right)$

$R I I_{c / i}$ - Relative Importance Index of category $c$ or indicator $i$.

$W I_{k}$ - Weight Index assigned to the opinion of the respondents of cluster $k$ (cluster $I=0.45$; cluster II $=0.31$; cluster III $=0.24$ )

$W_{j, k}$ - weight given by respondent $j$ of cluster $k$ considering the range from 1 to 5 , where 1 is the least important and 5 is the most important

$A$ - highest weight (5 in this case)

$n_{k}$ - total number of respondents of cluster $k$

\section{Presentation and analysis of results}

In practice, it is challenging to implement some EED criteria in healthcare buildings, mainly because healthcare service requires resource-intensive systems. For instance, the EED objective of achieving a smaller building footprint is in straight conflict with the EBD approach of single patient rooms. Another example is the importance of water reduction and the reuse of grey water that can be a challenge in healthcare context due to infection control issues and code conflicts. Although HBSA methods have been trying to incorporate and solve these issues, they also need to have a clear structure and assessment methodology to be easy to use.

In general, the proposed HBSAtool-PT method is based on fifty-two SED indicators that are assembled into twenty-two categories, which in turn are subdivided into five areas. Analysing the structure and the list of indicators of the new method it is possible to identify some new SED criteria that are not integrated with the building sustainability assessment methods developed so far. Therefore, the results presented in this chapter are focused on the new indicators and categories proposed. The intention is to present and validate the new indicators in the context of global SED criteria structure proposed.

\subsection{List of Sustainable-Effective Design (SED) criteria}

The proposed HBSAtool-PT is aimed at allowing a comparison of the overall performance of healthcare buildings projects. The list of indicators, categories and areas recommended in this article was evaluated by a group of researchers and experts as presented before. The adaptive learning process for developing and applying sustainability indicators used, has often been shown to be more precise and sometimes easier to apply (Reed et al., 2006).

Table 3, presents the proposed list of SED criteria, structured by areas, categories and indicators. The proposed structure for the new HBSAtool-PT method is based on EBD, EED and other complementary criteria to meet the sustainability goals. Therefore, the new SED concept proposed is defined by criteria that promote medical and workspace concerns, environmental issues, but also economic, social, technical and local needs, always considering the concept of sustainable built environment.

As presented in Table 3, the following categories were added to the EBD and EED categories in order to reach the following objectives: Soil use and biodiversity (C3); Landscaping (C8); Passive design (C9); Mobility plan (C10); Space flexibility and adaptability (C11); Durability (C17); Cultural value (C21); Facilities (C22).

\subsection{Relative importance of the new proposed SED design criteria}

Considering Table 3, there are eight SED complementary categories in a set of twenty-two, distributed among the different areas, except Economy. Each of these categories is composed of a different number of indicators, making an overall number of twenty-one in a total of fiftytwo.

After that, the results obtained in the questionnaire were analysed to understand the relative importance of each identified category in the overall of list proposed. Fig. 3 presents how each category is ranked by each cluster of stakeholders, using a scale between 1 (not important) to 5 (very important).

It is important to note that 5 and 4 levels were the best of all options in the categories analysed. In some cases, they were the only levels chosen, as in category $8,10,11,21$ and 22 , considering the opinion of stakeholders belonging to Cluster II. Level 1 was the less attributed score, having no presence in most categories.

For a better analysis, Fig. 4 presents the relative importance of each category, using the RII index, where the calculation method was explained in sub-Section 2.4.1.

By analysing the range of RII values, it is possible to conclude that they vary between 0,72 (Category 8 - Landscaping) and 0,95 (Category 22 - Facilities). Thus, it is possible to conclude that all the respondents agree not only with the importance of the introduction of these categories in the proposed HBSAtoll-PT method but also that they all have great importance. Although there are no huge differences between the relevance of each mentioned category, it is possible to highlight Categories 22 (Facilities) and 17 (Durability) as being the most important.

\subsection{Categorising weights of categories and indicators}

\subsubsection{Categories}

Using the AHP method specified in Sub-Section 2.4.1, Fig. 5 presents the weight of each category inside the respective area. Analysing Fig. 5, it is conclusive that C3 (Soil use and biodiversity) is the less important in the Environmental area. In Sociocultural and Functional area, Categories 8, 9, 10 and 11 made up $50 \%$ of overall weight. Category 17 (Durability) has an average weight in the Technical area and Site area categories C21 (Cultural value), and C22 (Facilities) are the most important, with a weight of $70 \%$.

The results are entirely understandable, given the main concerns in the health sector: the users' comfort, the available facilities and respective quality and costs control.

\subsubsection{Indicators}

Regarding Table 3, each new SED category (corresponding to the green colour) has a different number of indicators. Respondents argued that all the proposed indicators are relevant and representative of the 


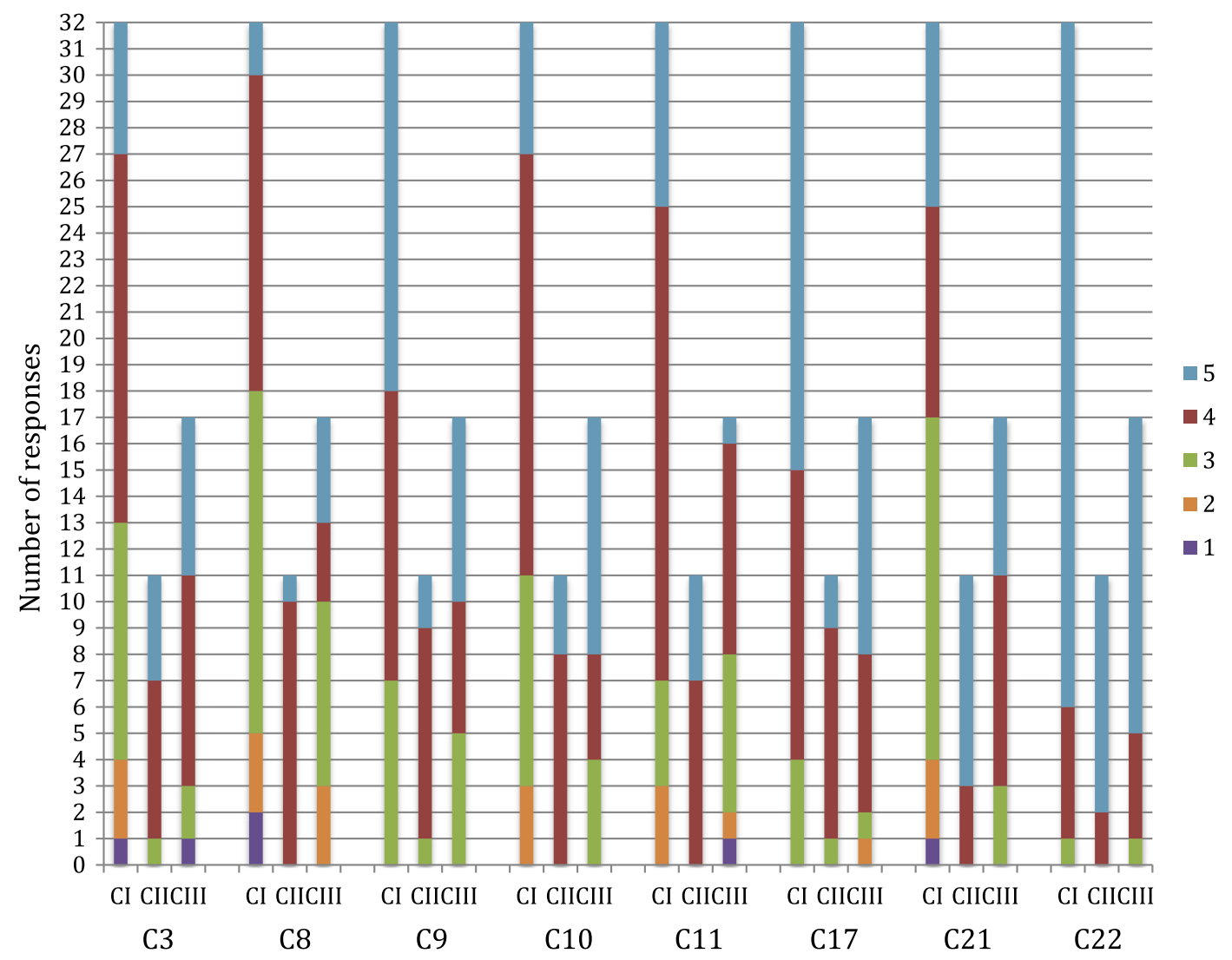

Fig. 3. Comparison between the ratings given to the new proposed categories.

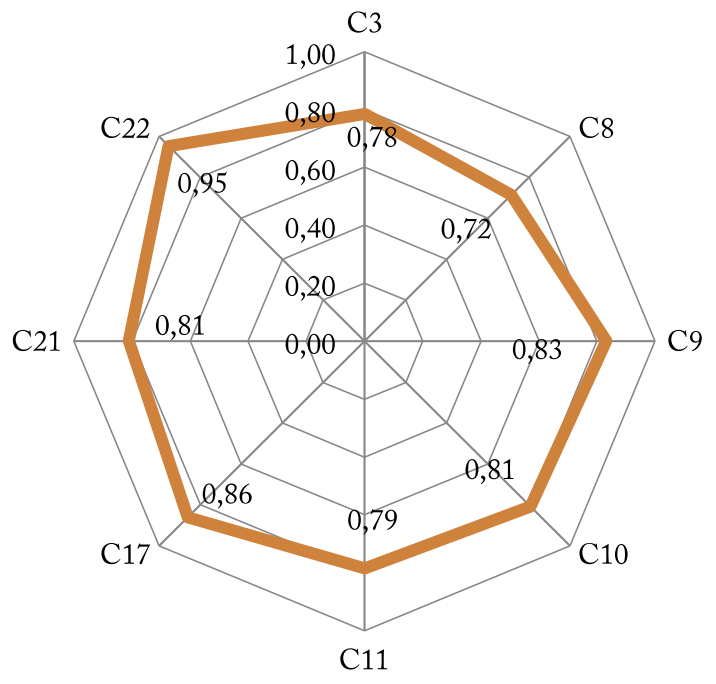

Fig. 4. Relative importance of each new proposed category.

category to which they belong. So, they agreed that this list should be considered in the HBSAtool-PT method per selected SED criteria.

Taking into account each indicator, the respondents were asked to set the relative weight in the assessment of the performance at the level of each category. As a result of applying the method presented before, Table 4 shows the weights assigned to each indicator to assess the performance of the healthcare buildings at the level of each sustainability area.

By analysing each category, it is possible to highlight the most important indicator, according to the opinion of the responders:

- Category 3 (Soil use and biodiversity) - the most important is I4
(Layout optimisation), closely followed by I6 (Reuse of previously built or contaminated areas);

- Category 9 (Passive design) - I27 (Passive Systems) has relatively more weight than I26 (Layout and Orientation);

- Category 11 (Space flexibility and adaptability) - the most important are I29 (Availability of and accessibility to social areas), but the other three indicators have a balanced weight;

- Category 17 (Durability) - I42 (Materials of high strength and durability) has relatively more weight than I43 (Proper selection of furniture);

- Category 22 (Facilities) - the most important indicator is I50 (Accessibility to public transport).

\subsection{Methodologies to evaluate qualitative and quantitative indicators}

Most of the criteria that compose existing HBSA methods are selected by regarding the limits of objective, scientifically acknowledged and verifiable factors (Cole, 1999). But this way can only offer a partial view of sustainable performance. Nonetheless, seeking the introduction of new criteria, more qualitative descriptions in the measurement scale are needed because the measures of the performance are currently weakly defined. This kind of criteria can be easily criticised as missing the objectivity required to promote confidence in the assessment system (Cole, 1999). Reasoning for this is that qualitative indicators are open to wider interpretation since their evaluation is normally less precise. To introduce qualitative indicators in HBSA methods, it is important to reduce misinterpretation, by establishing precise and objective assessment scales (Ng et al., 2013). To be successful the proposed assessment scales must be submitted to the analysis of third party stakeholders, using, for instance, questionnaires.

In proposed HBSAtool-PT structure there are quantitative and qualitative indicators.

To support the further development of the HBSAtool-PT, the 


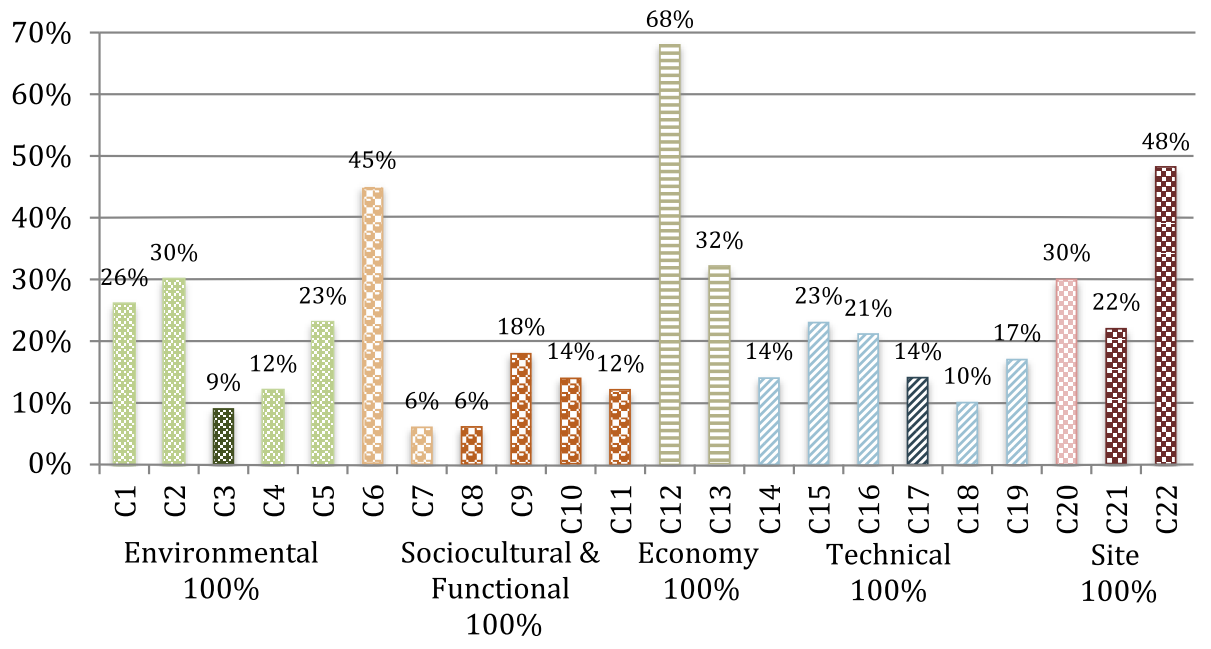

Fig. 5. Weighting of SED categories in overall categories of each area.
Table 4

Weight of each indicator in the quantification of building performance at the level of each new proposed sustainability category.

\begin{tabular}{lll}
\hline ID & Designation & Weight (\%) \\
\hline C3 & Soil use and biodiversity & 100 \\
I4 & Layout optimisation & 68 \\
I5 & Soil sealing & 15 \\
I6 & Reuse of previously built or contaminated areas & 19 \\
I7 & Ecological protection of the site & 16 \\
I8 & Rehabilitation of the surrounding & 10 \\
I9 & Use of native plants & 7 \\
I10 & Heat island effect & 8 \\
C8 & Landscaping & 100 \\
I25 & Visual link with the surrounding landscape & 100 \\
C9 & Passive design & 100 \\
I26 & Layout an Orientation & 38 \\
I27 & Passive Systems & 62 \\
C10 & Mobility plan & 100 \\
I28 & Accessibilities & 100 \\
C11 & Space flexibility and adaptability & 100 \\
I29 & Availability and accessibility to social areas & 31 \\
I30 & Space optimisation & 21 \\
I31 & Space flexibility & 24 \\
I32 & Space adaptability & 25 \\
C17 & Durability & 100 \\
I42 & Materials of high strength and durability & 71 \\
I43 & Proper selection of furniture & 29 \\
C21 & Cultural value & 100 \\
I49 & Heritage framework & 100 \\
C22 & Facilities & $\mathbf{1 0 0}$ \\
I50 & Accessibility to public transport & 58 \\
I51 & Low impact mobility & 24 \\
I53 & Local amenities & 18 \\
\hline & & \\
\hline & & \\
& &
\end{tabular}

following three sub-sections give examples of how to assess both qualitative and quantitative indicators. As an example, indicators from two previously studied categories are selected: C8- Category Landscaping; and C11 - flexibility and adaptability.

\subsubsection{Indicator visual connection with the surrounding landscape (I25)}

The qualitative indicator I25 (visual connection with the surrounding landscape) is presented as an example of the evaluation of almost of all qualitative indicators proposed for the HBSAtool-PT. The used method is based on a checklist, considering the Portuguese context. This checklist includes all main issues that must be considered in each indicator, taking into account: the country laws or requirements; the recognised success case studies; the stakeholders' opinion; and the needs identified in the existing buildings in the country.

Therefore, regarding this particular Indicator, the contact with nature through "nature-related indoor décor, daylight, window views and direct access to the outdoor environment", produce multiple health benefits in the treatment and work environments of healthcare buildings (Nejati et al., 2016). Different studies have proved this statement, showing that the possibility of access to daylight, nature and/or outdoor environments are apparent to have significantly more rehabilitation potential in healthcare spaces (Nejati et al., 2016). Other studies, analysed the difference between "full physical access to the outdoor landscape" and the mere "visual contact through windows" and showed the superior benefits of the first one (Largo-Wight et al., 2011).

Based on these findings, the Indicator 25 (visual connection with the surrounding landscape) is assessed qualitatively through a list of sustainability principles and associated credits. When a design satisfies, or exceeds a boundary condition, it gathers the related credits. The overall performance of the design at this indicator results from the weighted average of the credits obtained by each evaluated room, considering the total number of rooms evaluated (Table 5).

For each of the three broad groups of existing interior spaces in healthcare buildings, presented in Table 5 below, several credits are

Table 5

Checklist to determinate total number of credits that one building can achieve in I25.

\begin{tabular}{|c|c|c|c|c|c|}
\hline Criteria & Type & Quality & $\begin{array}{l}\text { Credits } \\
A_{i}\end{array}$ & $\begin{array}{l}\text { Number of } \\
\text { rooms (from } \\
\text { workplace, } \\
\text { internment } \\
\text { and lounges) } \\
\text { that meet } \\
\text { each criterion } \\
B_{i}\end{array}$ & $\begin{array}{l}\text { Total } \\
\text { number of } \\
\text { rooms } \\
\text { under } \\
\text { evaluation } \\
n\end{array}$ \\
\hline \multirow{4}{*}{$\begin{array}{l}\text { Direct access to } \\
\text { the outdoor } \\
\text { environ- } \\
\text { ment }\end{array}$} & \multirow[t]{2}{*}{ Landscape } & Garden & 12 & & \\
\hline & & Nature & 11 & & \\
\hline & \multirow[t]{2}{*}{ Townscape } & City & 10 & & \\
\hline & & $\begin{array}{l}\text { Traffic } \\
\text { routes }\end{array}$ & 9 & & \\
\hline \multirow{4}{*}{$\begin{array}{l}\text { Direct access to } \\
\text { the outdoors } \\
\text { through a } \\
\text { balcony }\end{array}$} & \multirow[t]{2}{*}{ Landscape } & Garden & 8 & & \\
\hline & & Nature & 8 & & \\
\hline & \multirow[t]{2}{*}{ Townscape } & City & 7 & & \\
\hline & & $\begin{array}{l}\text { Traffic } \\
\text { routes }\end{array}$ & 6 & & \\
\hline \multirow{4}{*}{$\begin{array}{l}\text { An outdoor view } \\
\text { through a } \\
\text { window }\end{array}$} & \multirow[t]{2}{*}{ Landscape } & Garden & 4 & & \\
\hline & & Nature & 5 & & \\
\hline & \multirow[t]{2}{*}{ Townscape } & City & 3 & & \\
\hline & & $\begin{array}{l}\text { Traffic } \\
\text { routes }\end{array}$ & 2 & & \\
\hline \multirow{2}{*}{\multicolumn{3}{|c|}{$\begin{array}{l}\text { Existence of indoor natural plants } \\
\text { Building performance regarding the visual } \\
\text { connection with the surrounding }\end{array}$}} & 1 & & \\
\hline & & & & & \\
\hline
\end{tabular}


available: workplaces (for staff); internment (for patients); and lounges (for patients and visitors). In the end, the sum of a total number of credits is compared with best and conventional practices, according to the specific context in which the method is going to be applied.

\subsubsection{Indicators from category space flexibility and adaptability (C11)}

The flexibility of the spaces and the relationship between them, emerge as a mechanism to address the lack of a permanent link between the user, constantly "changing", and the designer. Devices that provide the desired space availability and the composition of the building allow accommodating different modes of use in situations that are limited at the outset. Thus, the flexibility in its various forms aims primarily at freeing the health sector of the negative aspects, so that the needed multi-functionality is achieved.

Therefore, the concept of flexibility can be subdivided into two major groups: the initial flexibility and continuous flexibility. The latter, in turn, can be subdivided into three concepts: mobility, evolution and elasticity (Eleb-Vidal et al., 1988). Adaptability is another way to understand the flexibility. The adaptive building admits many different functions at present and in the future. It also allows for the possibility of the change of use (Maccreanor, 1998).

Regarding these, the four indicators proposed in this category are aimed to decompose the concept of flexibility into measurable parameters to promote its assessment. Regarding the methods to assess the four indicators of the C11 category, the following approaches are proposed:

- I29 (Availability and accessibility to social areas) - has a similar assessment process to I25 (Sub-Section 3.4.1). The evaluation is based on a checklist that asks what kinds of social spaces exist in the building and how it is possible to access them.

- I30 (Space optimisation) - aims at rewarding the maximisation of the net internal building area, reducing the total construction area. It is based in the Space Efficiency (SE) index that is the ratio between the Net Internal Area (NIA) and the Total Gross Area (TGA). Eq. (3) presents the calculation method.

$S E=\frac{N I A}{T G A}$

$N I A=$ Net Internal Area is the area of all building compartments, calculated by the internal perimeter of external walls (excluding: internal walls, vestibules, ducts, bathrooms, interior corridors, storage areas, similar functional compartments and closets in the walls).

TGA $=$ Total Gross Area is the sum of the construction areas of all existing or planned buildings. This is the sum of the areas of all floors above and below the ground level, except for the areas in the attic and basement without minimum weight. The construction area is on each floor, as calculated by the exterior perimeter of the exterior walls, including the movement of covered spaces (halls, galleries, corridors, stairwells and lift shafts) and the outside covered spaces (porches, carports, porches and covered terraces).

- I31 (Space flexibility) - aims to reward the existence of flexible partitioning of the space. For this, it is necessary to consider the main vertical elements that usually exist to divide a space. So, the next two indexes are considered: Engaging Vertical Division Elements (EVDE) and Interior Vertical Division Elements (IVDE). Therefore, two Values Scales of Flexibility are used to quantify the versatility of each room groups studied (example hospital rooms, living rooms, operating rooms, etc.) and to achieve the Flexible Global Subdivision (FGS). These scales, presented in Table 6 and proposed by Davico (2013) are decimal and are between 0 and $9(0$ the least adaptable; 9 the most adaptable). Each value on the scale belongs to each type of partition (e.g. wall, door, sliding panel, etc.)..The FGS index is calculated using Eq. (4).
Table 6

Values for the Scales of Flexibility (Davico, 2013).

\begin{tabular}{lrll}
\hline EVDE & & IVDE & \\
\hline $\begin{array}{l}\text { Bellows wall with transparent } \\
\quad \text { surface }\end{array}$ & 8,8 & Mobile furniture & 9,0 \\
$\begin{array}{l}\text { Transparent sliding surface } \\
\text { Opaque sliding surface }\end{array}$ & 7,8 & Partition bellows & 7,5 \\
Transparent surface with curtain & 7,1 & Curtain & 7,1 \\
Transparent surface & 6,8 & Transparent sliding surface & 5,9 \\
Transparent door & 5,6 & Opaque sliding surface & 5,7 \\
Opaque door & 4,9 & Transparent door & 5,3 \\
Fixed panel with window & 4,4 & Opaque door & 4,3 \\
Fixed panel & 4,3 & Multifunctional fixed furniture & 3,8 \\
Fixed wall with window & 3,0 & Fixed furniture & 3,1 \\
Light fixed wall & 2,1 & Transparent fixed surface & 2,1 \\
Conventional wall (fixed) & 0,9 & Fixed light panel & 1,2 \\
& 0,0 & Conventional wall (fixed) & 0,0 \\
\hline
\end{tabular}

$F G S=\sum\left(\frac{l m_{E}}{T l m_{S C}} \times S V_{E}\right) \times 100$

$l m_{E}=$ Linear meters of each EVDE and/or IVDE presented in each room groups.

$T m_{S C}=$ Total linear meters of each room groups.

$S V_{E}=$ Scale value of each EVDE and/or IVDE.

- I32 (Space adaptability) - it is based on the calculation of the Global Adaptive Space (GAS) per bed. Eq. (5) presents the calculation method.

$G A S=\frac{\frac{N I A-I F A}{T G A}}{N B}=\frac{N I A-I F A}{N B \times T G A}$

IFA = Internal Fixed Area is the total of technical areas that present static condition relationship with adjacent spaces, usually composed by kitchens and bathrooms.

$\mathrm{NB}=$ Number of Beds.

\section{Discussion}

Considering that hospital buildings are large consumers of energy and water, have big dimensions, operates continuously, use a large quantity and variety of equipment and are always being updated - the sustainable design potentially results in a competitive advantage at economic, environmental and social levels. Furthermore, HBSA methods need to be based on a systematic approach to go with these multidisciplinary and complex sustainability goals. It is possible to highlight the following roles of the HBSA methods:

1. Take into account the connection between the sustainable development needs and the built environment;

2. Transform these requirements into achievable goals;

3. Establish references (at global, regional or national levels) and outstanding sustainability practices;

4. Be a useful aid in the decision-making process.

Hitherto, the existing HBSA identified methods have been trying to introduce in its structure the sustainable development aims, considering the building based design specifications. This paper proposed the definition of a new concept, which is Sustainable-Effective Design (SED). From this concept, it is possible to define some SED criteria capable of outlining a list of indicators, which could integrate an HBSA method. A proposed structure for the HBSAtool-PT method was presented, described and analysed.

Table 7 presents the relationship between the sustainable core categories of existing HBSA methods and proposed HSATool-PT at the three sustainability dimensions (and related sustainability aspects), according to the division suggested by ISO 21929-1: 2011 (ISO, 2011) 
Table 7

Potential impacts of the core categories of HBSA methods, according to ISO 21929-1:2011.

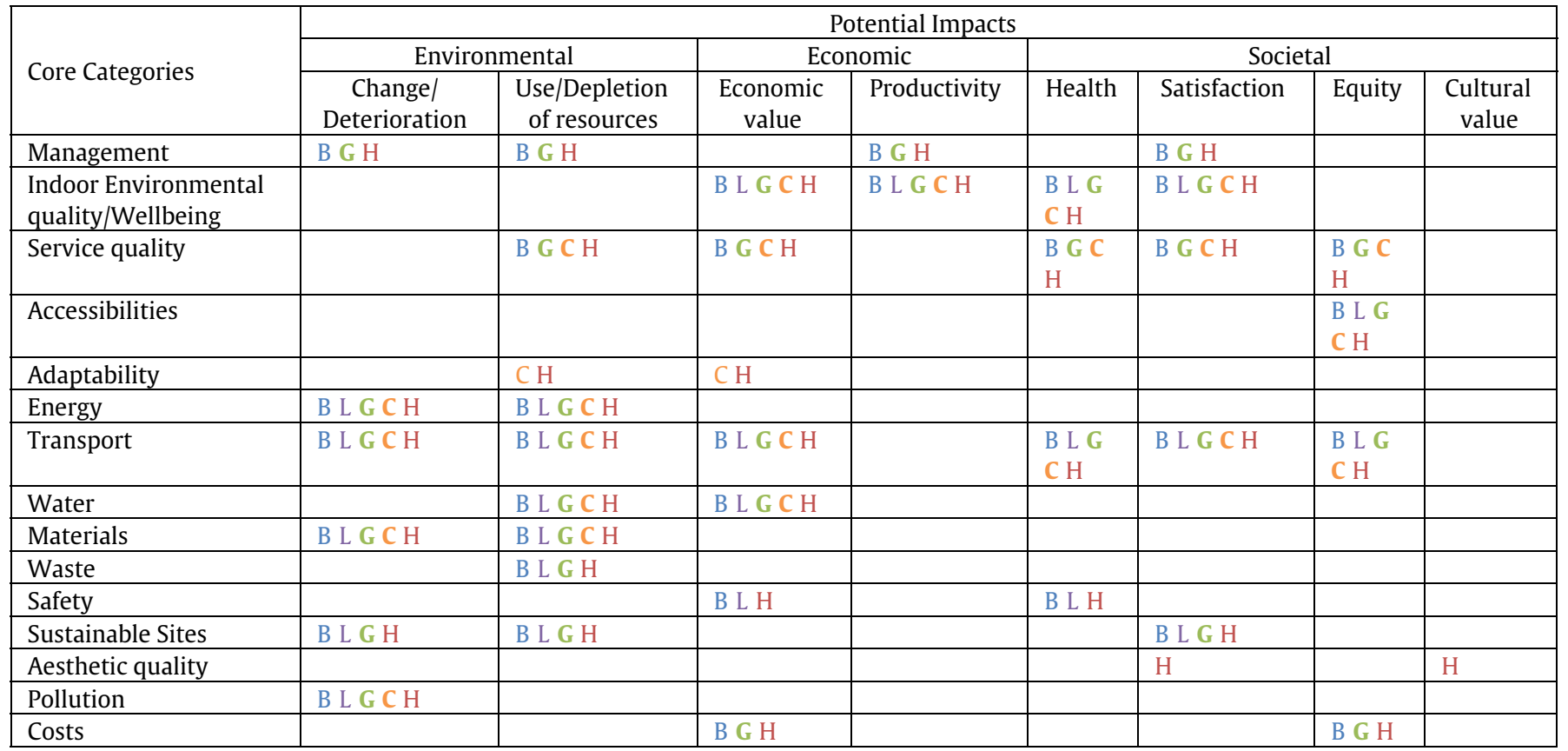

Legend: B - BREEAM UK New Construction; L - LEED BD + C; G - Green Star - Design \& As Built; C - CASBEE - NC; H - HBSAtool-PT

\section{(Kang et al., 2016).}

In Table 7 immediately stands out two columns for opposite reasons: the "cultural value" aspect considered only in Category 21 (Cultural Value) of the HBSAtool-PT, and "use/depletion of resources" aspects covered by most core sustainability categories presented in all five HBSA methods. Thus, it concludes that HBSAtool-PT includes all core categories proposed by ISO 21929-1:2011 and therefore it addresses more sustainability aspects than the methods developed so far. The proposed method is based on a more comprehensive list of indicators than the currently existing HBSA methods. So, the SED concept allows a better response to sustainable building definition proposed by the standards, namely ISO 21929.

For the assessment of the proposed list of indicators, it is necessary to break down the building into its constituent parts and study each one: rooms; building; healthcare complex; and community. As well it is important to know what type and size of building is under study:

- Type of healthcare building (University hospital; General acute hospital; Health centres and clinics) (ACSS, 2012)

- Size (with less than three hundred beds; between three hundred and four hundred; over four hundred) (Caetano, 1972)

Depending on the type of building, the needs and mandatory requirements are also different and therefore, to be comparable, the case studies should be identical. In the case of the proposed method, university hospital and general acute hospital are considered, and the number of square meters is the measure that is used to dived the buildings in different groups (Castro et al., 2015b). The benchmarks used by each indicator are different, according to the size and the type of the building in study.

It is also important to highlight that in the case of this kind of buildings it is essential to evaluate space efficiency and consider the following aspects:

- Unlike other building types, in healthcare buildings, there are much more space typologies (technical areas, medical offices, nursery areas, societal areas, among others). Each different typology has different functionality requirements and therefore the indicators must be developed to allow the evaluation of the specific requirements of each one;

- When comparing the space efficiency of healthcare buildings, it is necessary to have in mind that the number of beds of each one is a variable that has a great impact on the results;

- Compared to other building types the operation period of healthcare buildings is quite different (most of this type of buildings operate in a $24 / 24$ h' service) and therefore the amount of time space is used is also very different.

To design a healthcare building taking into account space efficiency, it is necessary to consider (based on (Marmot, 2006)):

- The minimum necessary space for the desired functions to be properly accommodated, bearing in mind the comfort of the users;

- The high level of space utilisation because it is used for the maximum possible amount of time.

SED criteria can also promote fewer lifecycle costs by:

- Modifying and adapting space when functional requirements change, which permits the reuse of buildings in the long-term;

- Designing building spaces to optimised the use costs of their being used;

- Providing spaces, which are durable.

\section{Conclusions}

The integration of SED criteria in the design of hospitals can help to produce significant benefits when compared to the results of standard practices in healthcare buildings. Sustainable-Effective Design (SED) is a process of design that is based simultaneously on the effective medical 
functionality principles and the best trade-off between the environmental, economic and societal concerns of the Sustainable Development. This new concept also contributes to the definition of the criteria and framework to be adopted in the HBSA methods and highlights the importance of taking integrated design decisions.

The new proposed SED criteria, described and presented in Section 3.1, are more related to architectural concerns than the existing approaches, and can be easily answered by the architectural project design. These concerns normally require a qualitative approach and therefore it is necessary to resort to a methodology to assess the different perspectives of key stakeholders about these issues. This is of upmost importance to achieve a representative and consistent results, but it is also very complex and time consuming. This is why these issues are less focused on other building sustainability assessment methods already available on the market.

Comparing the HBSAtool-PT method with other existing approaches, it is possible to say that it allows for the integration of more comprehensive social and economic concerns, rather than focusing on reducing potential environmental impacts. If the decisions are made at the early stage, it is possible to integrate SED criteria with a greater probability of success, reducing costs, increasing the durability of the building, and promoting a better experience for all users. Comparing to other building types, it is necessary to highlight that healthcare buildings need to be more frequent renovated and adapted, in terms of space and layout, to integrate the fast technological evolution that is taking place in the healthcare sector.

\section{Acknowledgments}

The authors acknowledge the Portuguese Foundation for Science and Technology and POPH/FSE for its financial support for this study (Reference SFRH/BD/77959/2011). A special thank you is also addressed to Donald Ellis for proofreading the English text.

\section{References}

ACSS, 2012. Recomendações e especificações técnicas do Edifício Hospitalar, 2011 ed. ACSS, Lisboa.

Ali, H.H., Al Nsairat, S.F., 2009. Developing a green building assessment tool for developing countries - Case of Jordan. Build. Environ. 44, 1053-1064. http://dx.doi.org/ 10.1016/j.buildenv.2008.07.015.

Allacker, K., Khan, A., 2015. Introduction to architecture and sustainability: critical perspectives for integrated design. In: Khan, A., Allacker, K. (Eds.), Architecture and Sustainability: Critical Perspective for Integrated Design, 1st ed. ACCO, Brussels, pp. $13-36$.

Barbosa, M.T.G., Almeida, M., 2017. Developing the methodology for determining the relative weight of dimensions employed in sustainable building assessment tools for Brazil. Ecol. Indic. 73, 46-51. http://dx.doi.org/10.1016/j.ecolind.2016.09.017.

Baum, M., Shepley, M., 2009. Eco-Effective Design \& Evidence-Based Design. Cleanmed, Chicago, pp. 1-63.

Baum, M., Shepley, M., Ginberg, R., Rostenberg, B., 2009a. Eco-effective design and evidence-based design: perceived synergy and conflict. Herd 2, 56-70.

Baum, M., Shepley, M., Rostenberg, B., Ginberg, R., 2009b. Eco-Effective Design and Evidence-Based Design: Removing Barriers to Integration, 1st ed. AIA Board Knowledge Committee, San Francisco.

Caetano, E., 1972. Instalações e equipamentos hospitalares. Sociedade Industrial de Tipografis, Lda, Lisboa.

Castro, M.F., Mateus, R., Bragança, L., 2013. Improving sustainability in healthcare with better space design quality. In: Bártolo, H. (Ed.), SIM 2013-International Conference on Sustainable Intelligent Manufacturing, Lisbon, pp. 101-106.

Castro, M.F., Mateus, R., Bragança, L., 2014. Proposal for a Healthcare Building Sustainability Assessment (HBSA) Method, in: World SB14 Barcelona, 1st ed. World SB14, Barcelona, pp. 607-613.

Castro, M.F., Mateus, R., Bragança, L., 2015a. A critical analysis of building sustainability assessment methods for healthcare buildings. Environ. Dev. Sustain. 17, 1381-1412. http://dx.doi.org/10.1007/s10668-014-9611-0.

Castro, M.F., Mateus, R., Serôdio, F., Bragança, L., 2015b. Development of benchmarks for operating costs and resources consumption to be used in healthcare building Sustainability assessment methods. Sustainability 7, 13222-13248. http://dx.doi. org/10.3390/su71013222.

Castro, M.F., Mateus, R., Bragança, L., 2017. Development of a healthcare building sustainability assessment method-proposed structure and system of weights for the Portuguese context. J. Clean. Prod. 148, 555-570. http://dx.doi.org/10.1016/j. jclepro.2017.02.005.

CEN TC 350, EN 15643-2, 2011. Sustainability of Construction Works - Assessment of
Buildings - Part 2: Framework for the Assessment of Environmental Performance, 2011 ed. CEN, Brussels.

CEN TC 350, EN 15643-3, 2012a. Sustainability of Construction Works-Assessment of-Buildings_-Part 4: Framework for the Assessment of Social Performance, 2012 ed. CEN, Brussels.

CEN TC 350, EN 15643-4, 2012b. Sustainability of Construction Works-Assessment of-Buildings-Part 4: Framework for the Assessment of Economic Performance, 2012 ed. CEN, Brussels.

Clark, P., Malone, M., 2006. What patients want: designing and delivering health services that respect personhood. In: Marberry, S. (Ed.), Improving Healthcare with Better Building Design, 1st ed. Health Administration Press, Chicago, pp. 15-35.

Cole, R.J., 1999. Building environmental assessment methods: clarifying intentions. Build. Res. Inf. 27, 230-246. http://dx.doi.org/10.1080/096132199369354.

Cotter, M., Berkhoff, K., Gibreel, T., Ghorbani, A., Golbon, R., Nuppenau, E.-A., et al., 2014. Designing a sustainable land use scenario based on a combination of ecological assessments and economic optimization. Ecol. Indic. 36, 779-787. http://dx.doi.org/ 10.1016/j.ecolind.2013.01.017.

Davico, A., 2013. Avaliação da flexibilidade dos espaços de habitação: influência das divisórias e mobiliário. Escola de Engenharia da Universidade do Minho.

Dweiri, F., Al-Oqla, F.M., 2006. Material selection using analytical hierarchy process. Int. J. Comput. Appl. Technol. 26, 182-189.

Eleb-Vidal, M., Chatelet, A.-M., Mandoul, T., 1988. Penser l'habité - Le Logement en Questions, 2nd ed. Pierre Mardaga, Sprimont.

Fagbenle, O., Makinde, F., Oluwunmi, A., 2011. Factors influencing construction clients'/ contractors' choice of subcontractors in Nigeria. J. Sustain. Dev. 4. http://dx.doi.org/ 10.5539/jsd.v4n2p254.

Guenther, R., 2009. Sustainable architecture for health: a mindset shift. Herd 2, 3-9. http://www.herdjournal.com/ME2/dirmod.asp?nm = ArtIcles\%2FNews\&type = Abstract\&mod $=$ Publications\%3A\%3AArticle\&mid $=$ 8F3A7027421841978F18BE895F87F791\&tier $=1$ \&id $=$ CBAB00628A3B43E386FB083855A3C685.

Haapio, A., Viitaniemi, P., 2007. Environmental criteria and indicators used in environmental assessment of buildings. In: CIB (Ed.), CIB World Building Congress 2007, 2007 ed. pp. 14-17 (Cape Town).

Hambali, A., Sapuan, S.M., Ismail, N., Nukman, Y., 2010. Material selection of polymeric composite automotive bumper beam using analytical hierarchy process. J. Cent. S. Univ. Technol. 17, 244-256. http://dx.doi.org/10.1007/s11771-010-0038-y.

Heynen, H., 2013. Space as receptor, instrument or stage: notes on the interaction between spatial and social constellations. Int. Plan. Stud. 18, 342-357. http://dx.doi. org/10.1080/13563475.2013.833729.

Hsiao, S.-W., 2002. Concurrent design method for developing a new product. Int. J. Ind. Ergon. 41-55. http://dx.doi.org/10.1016/S0169-8141(01)00048-8.

ISO, ISO/TS 21929-1, 2011. Sustainability in Building Construction - Sustainability Indicators - Part 1: Framework for the Development of Indicators for Buildings, 2011 ed. ISO, Geneva, pp. 2011.

Kang, H., Lee, Y., Kim, S., 2016. Sustainable building assessment tool for project decision makers and its development process. Environ. Impact Assess. Rev. 58, 34-47. http:// dx.doi.org/10.1016/j.eiar.2016.02.003.

Kurtz, J., Jackson, L., Fisher, W., 2001. Strategies for evaluating indicators based on guidelines from the environmental protection agency's office of research and development. Ecol. Indic. 1, 49-60. http://dx.doi.org/10.1016/S1470-160X(01)00004-8.

Largo-Wight, E., Chen, W., Dodd, V., Weiler, R., 2011. Healthy workplaces: the effects of nature contact at work on employee stress and health. Public Health Rep. 126, $124-126$.

Maccreanor, G., 1998. Adaptabilidad, A + T - Vivenda E Flexibilidade.

Marmot, A., 2006. Promoting Space Efficiency in Building Design, SMG. Lincoln.

Mateus, R., Bragança, L., 2011. Sustainability assessment and rating of buildings: developing the methodology SBToolPT-H. Build. Environ. 46, 1962-1971. http://dx. doi.org/10.1016/j.buildenv.2011.04.023.

Nejati, A., Rodiek, S., Shepley, M., 2016. Landscape and Urban Planning. vol. 148. pp. 132-138. http://dx.doi.org/10.1016/j.landurbplan.2015.12.012.

Ng, S.T., Chen, Y., Wong, J.M.W., 2013. Variability of building environmental assessment tools on evaluating carbon emissions. Environ. Impact Assess. Rev. 38, 131-141. http://dx.doi.org/10.1016/j.eiar.2012.07.003.

Othman, A.A.E., Hassan, T.M., Pasquire, C.L., 2005. Analysis of factors that drive brief development in construction. Eng. Constr. Archit. Manag. 12, 69-87. http://dx.doi. org $/ 10.1108 / 09699980510576907$.

Reed, M.S., Fraser, E.D.G., Dougill, A.J., 2006. An adaptive learning process for developing and applying sustainability indicators with local communities. Ecol. Econ. 59, 406-418. http://dx.doi.org/10.1016/j.ecolecon.2005.11.008.

Saaty, T.L., 1988. What is the Analytic Hierarchy Process? McGraw Hill, New York.

Saaty, T.L., 2008. Decision making with the analytic hierarchy process. Int. J. Serv. Sci. 1, $1-16$.

Stevanovic, M., 2015. A review on requirements and existing qualitative tools for designing sustainable large-scale healthcare facilities: a case study in the context of flanders. In: Cisbat 2015, pp. 1-6.

Verderber, S., 2010. Innovation in Hospital Architecture, 2010 ed. Routledge, New York. 


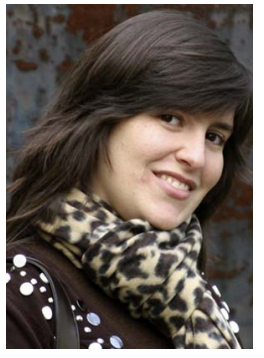

Maria de Fátima Castro is Architect and MSc in Sustainable Construction and Rehabilitation. At this moment she is a PhD student in a Doctoral Program of Civil Engineering, and her thesis theme is "Sustainability in the built environment: methodology to support sustainable building design hospital". She published one thesis in the field of sustainability and scientific papers (in an indexed journal) in the same research domain. She is an author identified by Web of Science and Scopus databases with several papers, and she has been participating in the organisation of several events in the field of Sustainable Construction. Since 2011, she has been participating through oral presentations on the topic at many international and national conferences, seminars and workshops, and several papers are published in conferences proceedings. She is member of the Technical Committee (TC) of iiSBE and responsible for TC of iiSBE Portugal secretariat, that aims to adapt the international building sustainability assessment tool "SBTool" to the Portuguese environmental, societal and economical contexts.

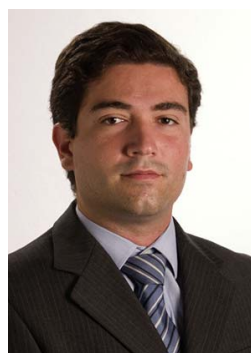

Ricardo Mateus is $\mathrm{PhD}$ in Civil Engineering, Assistant Professor at the Civil Engineering Department of the University of Minho and member of the C-TAC research unit. He is the author and co-author of several books and book chapters and more than sixty scientific papers in the same research domain. He received several awards for scientific and academic work developed, including: Honourable Mention Award "IHRU" (2010) and Honourable Mention Award “André Jordan" (2010). He is a member of several Organizations, Teams and Committees responsible for developing events, initiatives and normalization in the field of Sustainable Construction, with emphasis on the Coordination of the Technical Committee of iisBE Portugal.

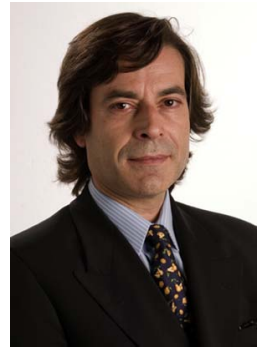

Luís Bragança is Professor at the Civil Engineering Department of the University of Minho, Master in Sustainable Construction and Rehabilitation and Building Physics and Construction Technology Laboratory director. He has authored and co-authored more than two hundred publications. He is currently President of the International Initiative for Sustainable Built Environment (iiSBE), Chairman of the Board of iiSBE Portugal, coordinator of the European COST Action C25, coordinator of the Committee for Education and Lifelong Learning of iiSBE and coordinator of the Technical Committee TC14 "Sustainability \& Eco-Efficiency of Steel Construction". Additionally, he takes part in the CEN/TC350 and is the representative of the Portuguese Construction Technology Platform in the European Construction Technology Platform. 